Article

\title{
Study on the Skid Resistance Deterioration Behavior of the SMA Pavement
}

\author{
Jincheng Wei ${ }^{1}$, Zhengchao Zhang ${ }^{1}$, Yulin $\mathrm{He}^{2}$, Qianwen Tan ${ }^{2}$, Xiangpeng Yang ${ }^{1}$, Dawei Wang ${ }^{2,3, * \mathbb{C}}$ \\ and Markus Oeser ${ }^{3}$
}

Citation: Wei, J.; Zhang, Z.; He, Y.; Tan, Q.; Yang, X.; Wang, D.; Oeser, M. Study on the Skid Resistance Deterioration Behavior of the SMA Pavement. Sustainability 2022, 14, 2864. https://doi.org/10.3390/ su14052864

Academic Editor: Ali

Bahadori-Jahromi

Received: 29 December 2021

Accepted: 24 February 2022

Published: 1 March 2022

Publisher's Note: MDPI stays neutral with regard to jurisdictional claims in published maps and institutional affiliations.

Copyright: (C) 2022 by the authors. Licensee MDPI, Basel, Switzerland. This article is an open access article distributed under the terms and conditions of the Creative Commons Attribution (CC BY) license (https:// creativecommons.org/licenses/by/ $4.0 /)$.
1 Science and Technology Innovation Center, Shandong Transportation Research Institute, Jinan 250216, China; 20s132085@stu.hit.edu.cn (J.W.); 21b932012@stu.hit.edu.cn (Z.Z.); 21b932021@stu.hit.edu.cn (X.Y.)

2 School of Transportation Science and Engineering, Harbin Institute of Technology, Harbin 150090, China; yulinhe@hit.edu.cn (Y.H.); tqw0617@163.com (Q.T.)

3 Institute of Highway Engineering, RWTH Aachen University, 52074 Aachen, Germany; oeser@isac.rwth-aachen.de

* Correspondence: wang@isac.rwth-aachen.de
Abstract: The skid resistance of asphalt pavement is of great importance to the driving safety, but deterioration of pavement skid resistance is inevitable owing to the coupling effect of traffic loading and climate conditions. The existing prediction models of skid resistance were mainly established based on the laboratory accelerated polishing tests (for instance Polished Stone Value, PSV), and these models can only consider the influence of a single factor; they fail to reflect the coupling effect of different factors under the real service condition. For the purpose of investigating the influences of seasonal variation, and aggregate type on the skid resistance of asphalt pavement, the skid resistance of three test tracks were continuously measured for 48 months through five different test methods. The results show that different test methods exhibit significant inconsistency. The aggregate type is the internal factor that determines the long-term skid resistance performance of pavement. The skid resistances of the selected test tracks were ranked as greywacke pavement $>$ diabase pavement $>$ rhyolite pavement. This is in well agreement with the ranking of aggregate polishing resistance obtained from the laboratory Wehner/Schulze (W/S) test. This indicates that the W/S test is effective in distinguishing the aggregates that used in pavement construction. It is also found that the skid resistance of asphalt pavement shows significant fluctuation with respect to seasonal variation. The skid resistance is generally high in autumn and low in summer. Therefore, it is suggested to use the low measurement value of skid resistance in summer as the lower limit for the evaluation and prediction of the skid resistance performance of asphalt pavement.

Keywords: traffic safety; asphalt pavement; skid resistance performance; seasonal variation; sensitivity fact

\section{Introduction}

Traffic accidents have long been a great challenge all over the world, and they are affected by numerous factors including driver behavior, vehicle, pavement, and climate as well as their coupling effect. A large number of studies have validated that about $30 \%$ of the total accidents are caused by the deterioration of pavement skid resistance [1-3]. The pavement surfaces with good skid resistance can provide adhesion to the vehicle tire, which in turn provides the vehicle with sufficient driving and braking forces [4-8]. The newly constructed asphalt pavement is always of good skid resistance, which ensures the safety of the traffic driving on it. However, the skid resistance of asphalt pavement would be continuously decreased because it was exposed to repeated vehicle loadings and cyclical climate changes [9-14]. Several previous research works have evidenced the seasonal variation of the skid resistance of asphalt pavement, and the asphalt pavement shows the best skid resistance in the winter and the worst in the summer $[15,16]$. In summer, 
the thermosensitive asphalt binder in pavement surface becomes soft because of the high temperature, and the exposed aggregates are compacted by the vehicles which leads to a smoother surface texture. In the winter and spring, the tire-pavement contact is of the best condition, and therefore, the asphalt pavement shows the best skid resistance. The coupling effect of cyclical climate and vehicle loading makes the investigation of skid resistance of asphalt pavement a very complex issue.

From the perspective of pavement life cycle, the deterioration of skid resistance normally consists of three stages. In the first stage, the skid resistance of asphalt pavement experiences a short and rapid increase. This increase is a result of the increase of pavement surface roughness because the attached asphalt binder at the surface was polished by the vehicle and the aggregates were fully exposed. This stage will last for 6 to 12 months. Then, the kid resistance of asphalt pavement starts to decrease because the exposed aggregates were gradually polished by the vehicle tires. The second stage is reported to be of the duration of two years. At the third stage, the skid resistance of asphalt pavement becomes nearly constant, and only slight fluctuations were observed [17-20].

Owing to the great importance of skid resistance of asphalt pavement, continuous research efforts have been devoted to the development of laboratory and field measuring methods. The existing test methods can generally be categorized into two groups. The first group refers to the indirect test where the surface texture of asphalt pavement was measured. The underlying mechanism of this group of test is that the macro and microtextures of pavement surface directly contribute to the skid resistance of asphalt pavement. An example of this group of test is the Macroscopic Texture Depth (MTD) test [21,22]. The second group refers to the tests which directly measure the skid resistance of the test sample or asphalt pavement. Examples of this category of tests include the British Pendulum Tester (BPT) test, the W/S test, the sideway force coefficient (SFC), the longitudinal friction coefficient (LFC) test, and others [23-30]. The BPT test mainly focuses on the low-speed skid resistance of pavement. Even though the BPT test is greatly affected by the tester, it is still one of the most commonly used tests all around the world. The W/S test describes the skid resistance of pavement through the dynamic friction coefficient $\mu_{\mathrm{W} / \mathrm{S}}$, a parameter that is believed to be more reasonable, and this method is highly recognized in Europe. The SFC and LFC are field text parameters, and they are obtained by using the one-wheeled friction measuring device pulled by a vehicle. These test parameters directly describe the friction performance between tire and pavement, but the test results are often found to be affected by many factors. Even though numerous developed test methods exist, none of them has ever been generally accepted by the researchers from around the world. The test results from different methods are even found to be in conflict with each other in some cases. Therefore, it is necessary to perform a comprehensive evaluation on the commonly used tests so as to figure out a reliable method.

The current study aims to exploit the sensitivity of the commonly used tests, and to identify the consistence of results from different tests. For this, five different test methods were selected, and the skid resistance of three test tracks was continuously measured. Based on the test results, the influences of test method, aggregate type and seasonal variation on skid resistance were identified.

\section{Materials and Methods}

\subsection{Aggregates and Test Tracks}

In the current study, three different kinds of mineral aggregates were used, which are diabase, rhyolite, and greywacke, respectively. These three selected aggregates were the most commonly used raw materials for the construction of asphalt pavement. The mineralogical properties of the three aggregates were measured through the XRD test, and the relative contents of the rock-forming minerals were presented in Figure 1 . The microtexture of selected three aggregates were identified through the thin cross-section test, and the results were shown in Figure 2. It could be found from Figure 2 that the microtexture of the three selected aggregates is significantly different. The rhyolite aggregate is of the 
greatest average crystal size $(234 \mu \mathrm{m})$, whereas the greywacke aggregate shows the smallest average crystal size $(45 \mu \mathrm{m})$.

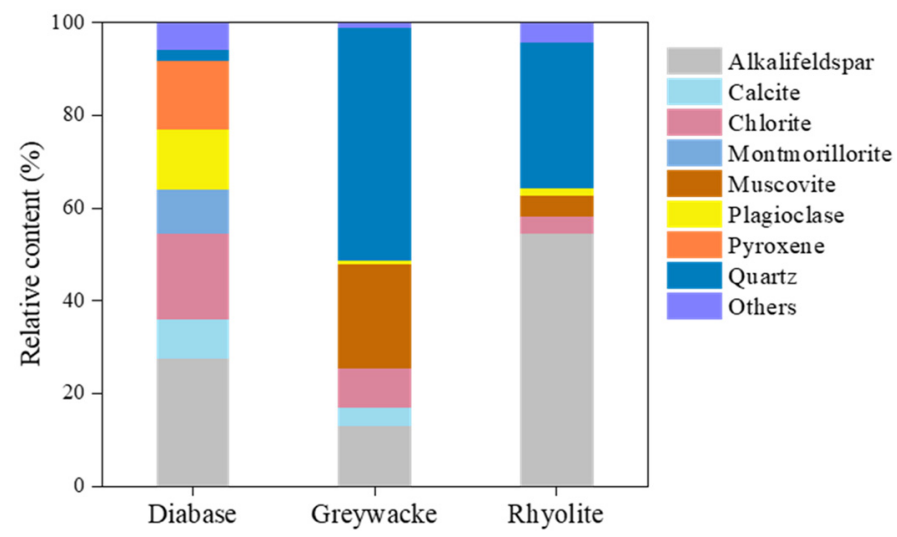

Figure 1. Mineralogical composition of the three aggregates [31,32].

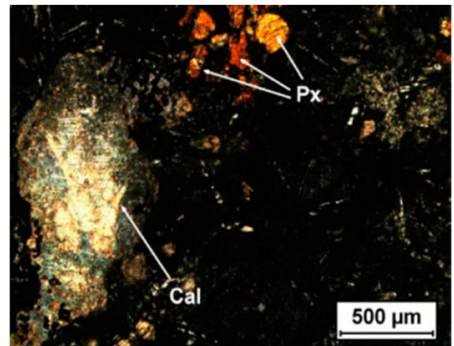

(a)

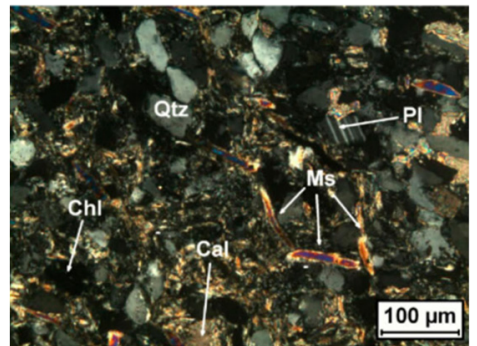

(b)

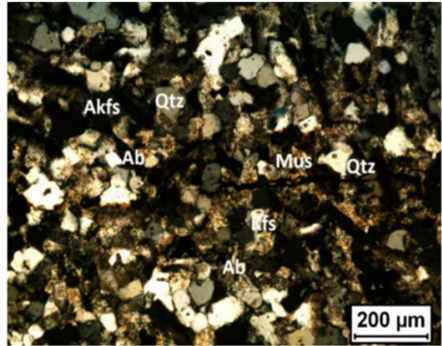

(c)

Figure 2. Microstructure of three aggregates using a thin cross section [31,32]. (a) Diabase (Crystal size: $165 \mu \mathrm{m}$ ); (b) Greywacke (Crystal size: $45 \mu \mathrm{m})$; (c) Rhyolite (Crystal size: $234 \mu \mathrm{m}$ ).

The skid resistance of the asphalt pavement is closely related to the micro and macrotextures of pavement surface as well as the polishing resistance of aggregates. The polishing resistance of the three selected aggregates have been extensively investigated in our previous studies [32]. Figure 3 depicts the evolutions of the dynamic friction coefficients $\mu_{\mathrm{W} / \mathrm{S}}$ of these three aggregates measured by the $\mathrm{W} / \mathrm{S}$ test. The nonlinear fittings were performed to quantify the relationship between polishing time and the dynamic friction coefficients $\mu_{\mathrm{W} / \mathrm{S}}$, and the fitting function and parameter values were given in Table 1 . Greater $\mu_{\mathrm{W} / \mathrm{S}}$ indicates better polishing resistance of the aggregate. The polishing resistance of aggregates is represented by the value of $\mu_{\mathrm{W} / \mathrm{S}}$ after the polishing process. Therefore, the greywacke exhibits the best polishing resistance, followed by the diabase and rhyolite aggregates.

Table 1. The fitting results of the W/S test for the selected aggregates.

\begin{tabular}{cccc}
\hline Test Track & Aggregate Type & Fitting Function & $\boldsymbol{R}^{\mathbf{2}}$ \\
\hline 1 & Rhyolite & $y=0.631-0.024 \ln (x-3.609)$ & 0.999 \\
2 & Diabase & $y=0.534-0.036 \ln (x-1.085)$ & 0.986 \\
3 & Greywacke & $y=0.544-0.032 \ln (x-0.584)$ & 0.981 \\
\hline
\end{tabular}

Three different test tracks were selected in the current study for the skid resistance measurement. The surface layers of the test tracks were paved by using the asphalt mixture of SMA-11S, which contains the three selected aggregates, respectively. The SMA-11S is the most commonly used asphalt mixture for the surface layer of highways in Germany, and the gradation of SMA-11S is given in Figure 4. The test tracks comprise rhyolite, diabase and greywacke aggregates were named as test track 1, 2, and 3 hereafter. 


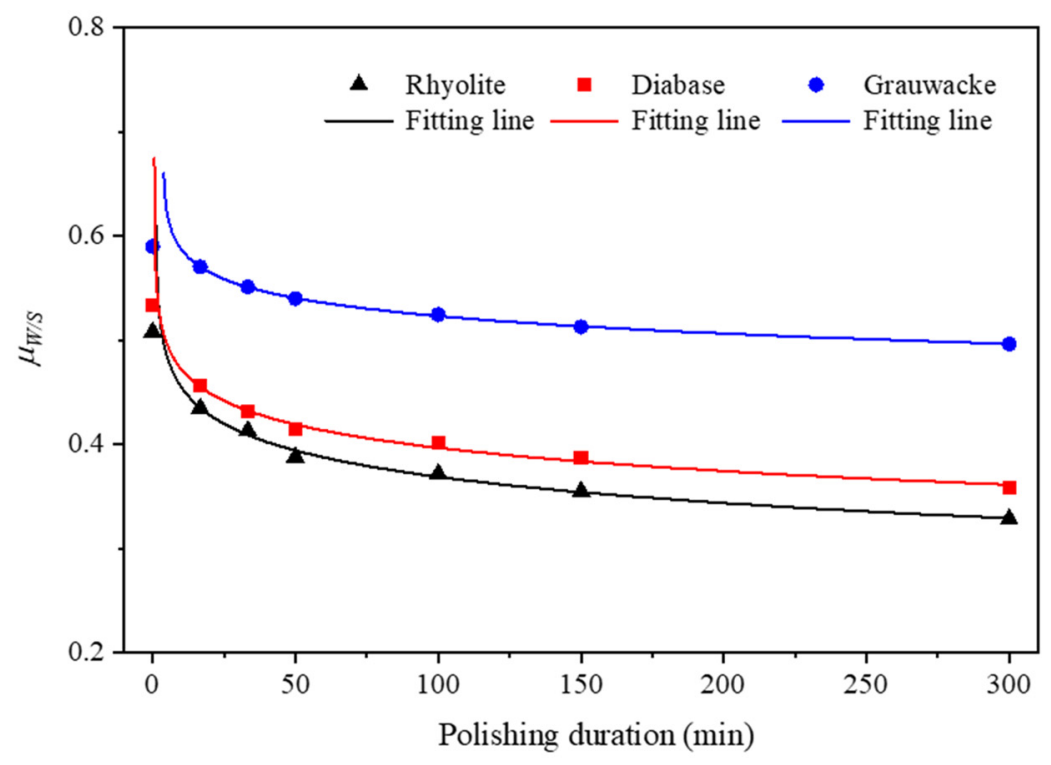

Figure 3. Evolution of the dynamic friction coefficient $\mu_{\mathrm{W} / \mathrm{S}}$ of aggregate.

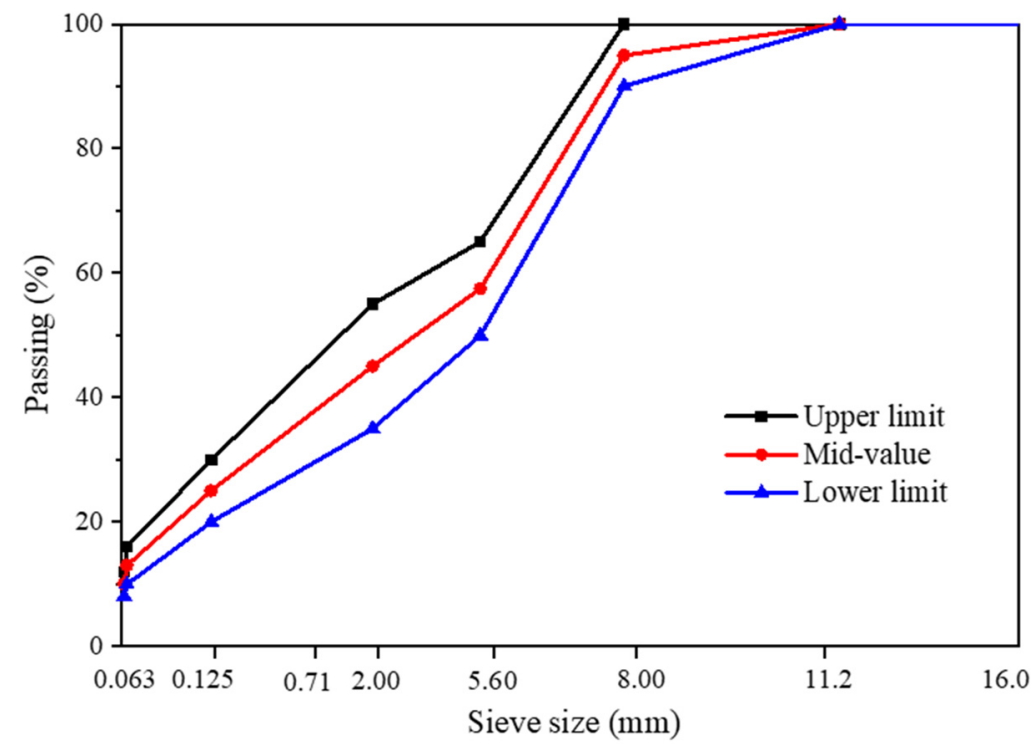

Figure 4. The gradation of SMA-11S asphalt mixture.

\subsection{Skid Resistance Tests}

Numerous test methods have been developed in the past for the evaluation of the skid resistance of asphalt pavement. In this study, five different kinds of tests were adopted for the measurement of skid resistance of the test tracks exposed to varying time duration of traffic. The tests include the BPT test, the MTD test, the Outflow Meter (OFM) test, the $\mathrm{W} / \mathrm{S}$ test, and the LFC test, as listed in Table 2. The BPT test is a commonly used method for the measurement of skid resistance of pavement surface. The test was conducted by measuring the low-speed friction at about $10 \mathrm{~km} / \mathrm{h}$ according to DIN EN 13036-4, and the obtained friction coefficient is named as British Pendulum Number (BPN). The OFM test measures the macrotexture of the surface course, and the outflow time of water between the two float switches of a vertical cylinder is verified with a stopwatch at the measurement points used for the measurements. The measurement parameter outflow time (OFT) defines the macrotexture of the pavement surface. Pavement surfaces with smooth macrotexture have high measurement results, and vice versa. The MTD is calculated from the threedimensional data of the macrotexture which is measured by a high-resolution optical profilometer following the procedure of DIN EN 13036-1. 
Table 2. The test methods and indexes of the pavement skid resistance.

\begin{tabular}{ccl}
\hline Test Method & Index & \multicolumn{1}{c}{ Reference } \\
\hline BPT & BPN & DIN EN 13036-4 \\
MTD & MTD & DIN EN 13036-1 \\
OFM & AM & ASTM E 2380-12 \\
W/S & $\mu_{\mathrm{W} / \mathrm{S}}$ & EN12697-49 \\
LFC & LFC & CEN/TS 15901-15 \\
\hline
\end{tabular}

The W/S test was conducted using the Wehner/Schulze machine, as shown in Figure 5 . The Wehner/Schulze machine is comprised of two units, one for polishing the test sample under certain speed and contact pressure, and the other for the measurement of friction. The friction measurement unit contains three rubbers attached to the circle plate which is of the diameter of $18 \mathrm{~cm}$. Each of the rubbers is of $14.5 \mathrm{~mm}$ width and of $30 \mathrm{~mm}$ length. During the friction measurement, the circle plate was firstly accelerated to the speed of $100 \mathrm{~km} / \mathrm{h}$. Then, the plate was lowered to be in contact with the test sample until it reached the stationary state. The coefficient of friction was continuously recorded during this process. Normally, the value corresponds to the speed of $60 \mathrm{~km} / \mathrm{h}$ is employed as the standard measurement result, i.e., the dynamic friction coefficient $\mu_{\mathrm{W} / \mathrm{S}}$. More details regarding the W/S test refer to the EN12697-49 as well as the previous studies [14,23].

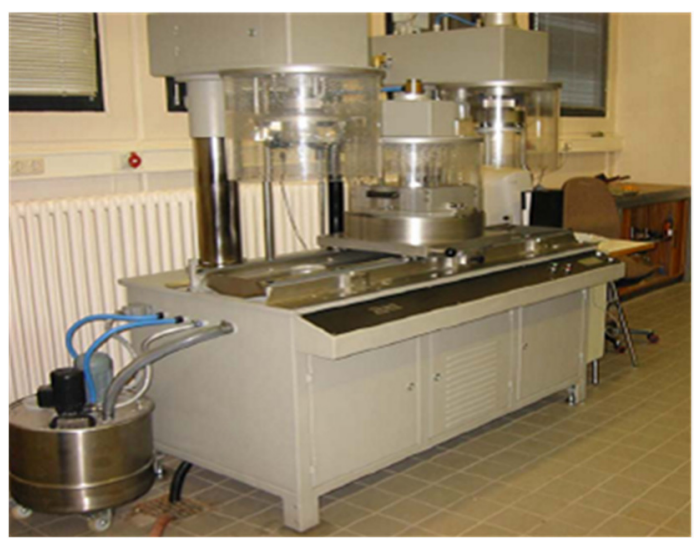

Figure 5. The Wehner/Schulze machine [14,23].

The LFC test was conducted by virtue of the ViaFriction test system as seen in Figure 6. The ViaFriction is a one-wheeled friction measuring device pulled by a vehicle, and it is designated a CFME (Continuous Friction Measuring Equipment). During the test, the friction between the measuring wheel and the pavement surface is continuously measured under variable slip rate. This is achieved by conducting wheel braking from free rolling to almost fully-locked and measuring the breaking friction force which the road surface exerts against the breaking wheel. As a result, the so-called $\mu$-slip-curve is obtained, and the maximum value of the friction coefficient $\mu$ max is adopted as a realistic assessment of skid resistance due to the large presence of ABS braking systems for cars and trucks today $[24,25]$.

In this study, the skid resistance measurement of the three test tracks were conducted in April, August and October of the test years to investigate the seasonal influence. The measurement continued for 48 months. April is selected to represent the climate conditions of spring, and August and October are for summer and autumn, respectively. The measurement was not implemented in the winter season because the determinant factor that affects the skid resistance of asphalt pavement is snow, but all the involved tests in the current study cannot describe this well. 


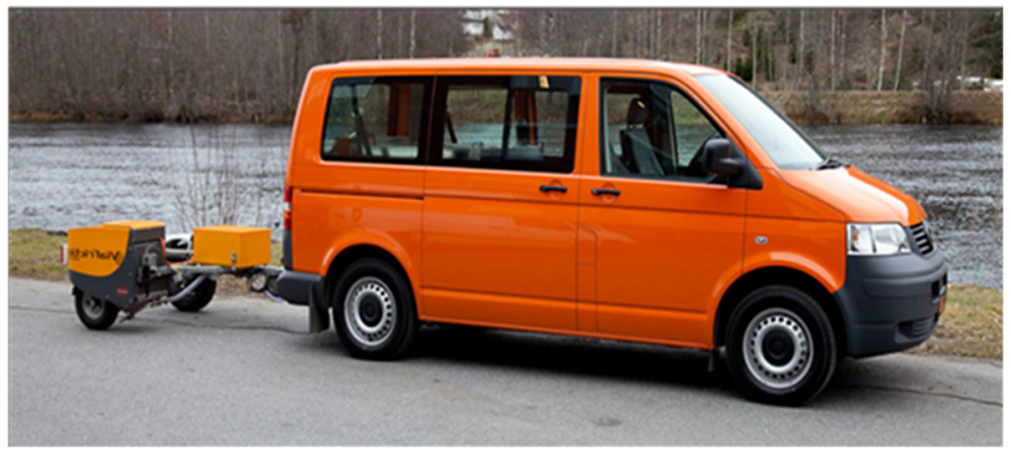

Figure 6. The ViaFriction test system [24,25].

\section{Results and Discussion}

\subsection{Skid Resistance Development of Test Tracks}

\subsubsection{Deterioration Behavior of Different Skid Resistance Indexes}

Considering that the underlying mechanisms of different skid resistance tests are not exactly the same, the sensitivities of different methods to the micro and macro-characteristics of asphalt pavement surface would be very different. To fully describe the skid resistance deterioration behaviors of the test tracks, five tests were adopted among which the LFC test is a kind of field test whereas others are laboratory tests. The measurement results of different methods were shown in Figures 7-11, respectively.

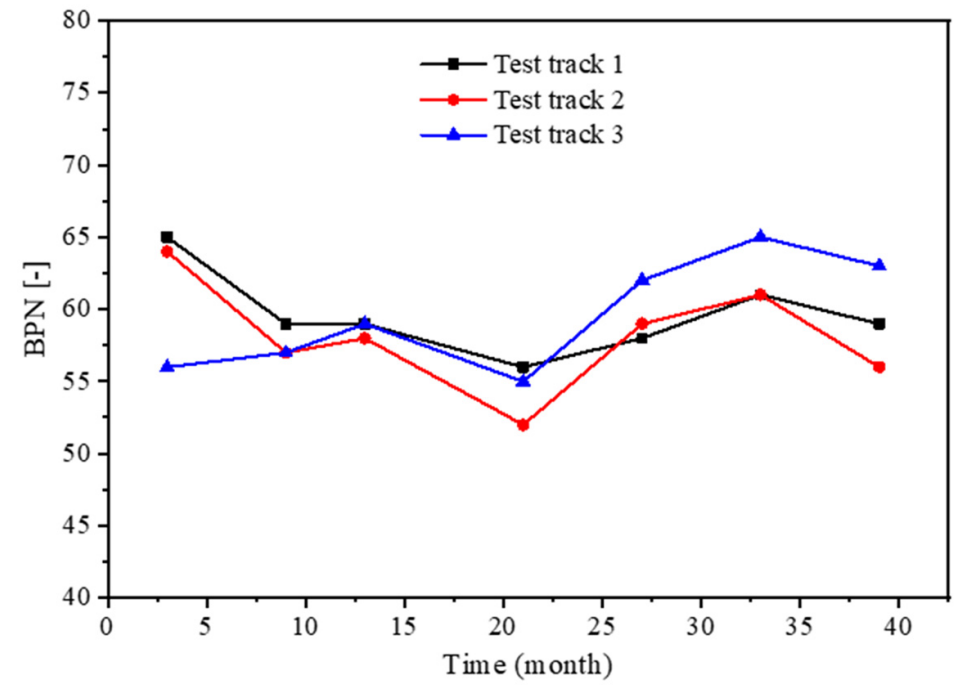

Figure 7. The BPT test results of different tracks.

It could be easily found from the figures that the BPT test, W/S test, and LFC test results exhibit similar evolution law that no significant increase or decrease was observed for the measured values. The minor fluctuations observed for these parameters can be attributed to the disturbances from polishing media (dust and water) and cyclical climate changes, e.g., temperature. The MTD results of the test tracks obviously decrease with the increase in time duration within the beginning 15 months, after which they become nearly constant. The OFT results of the test tracks generally increase with the increase of time duration across the whole test duration. The decrease of the MTD index and increase of the OFT index are the direct results of surface aggregate polishment by the vehicle tire. It is worth noting that the skid resistance of the test track 3 in Figure 11 exhibits slight increase after about 10 months of measurement. This is likely to be related to the affinity property between bitumen aggregate. The test track 3 uses greywacke aggregate which generally shows poor adhesion performance to bitumen binder comparing to the other two aggregates. As a result, the bitumen film is more easily polished by the vehicle tire 
and the aggregates are exposed. This would increase the roughness of pavement surface microtexture, and the skid resistance of test track 3 is therefore improved.

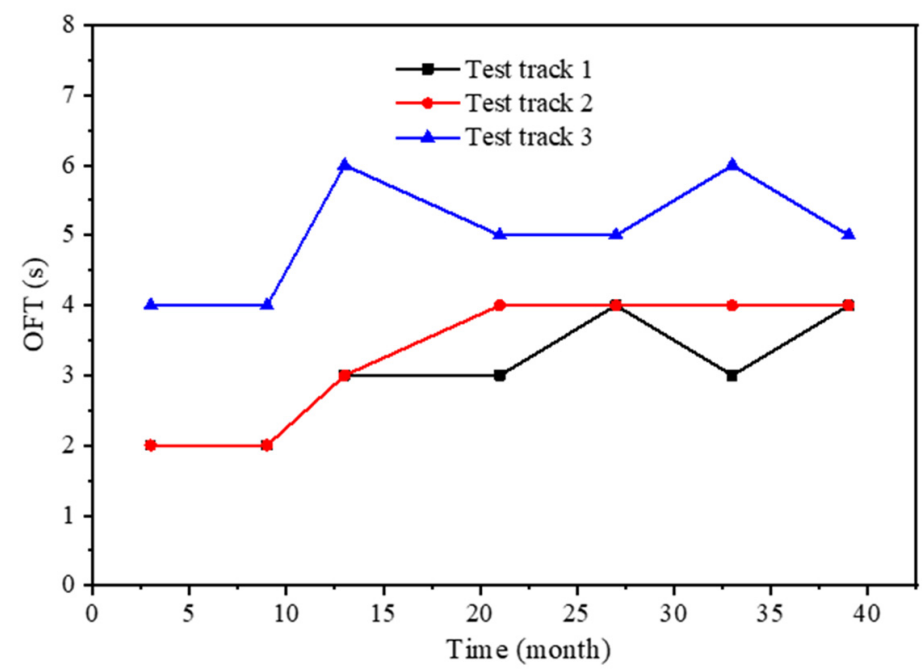

Figure 8. The OFM test results of different tracks.

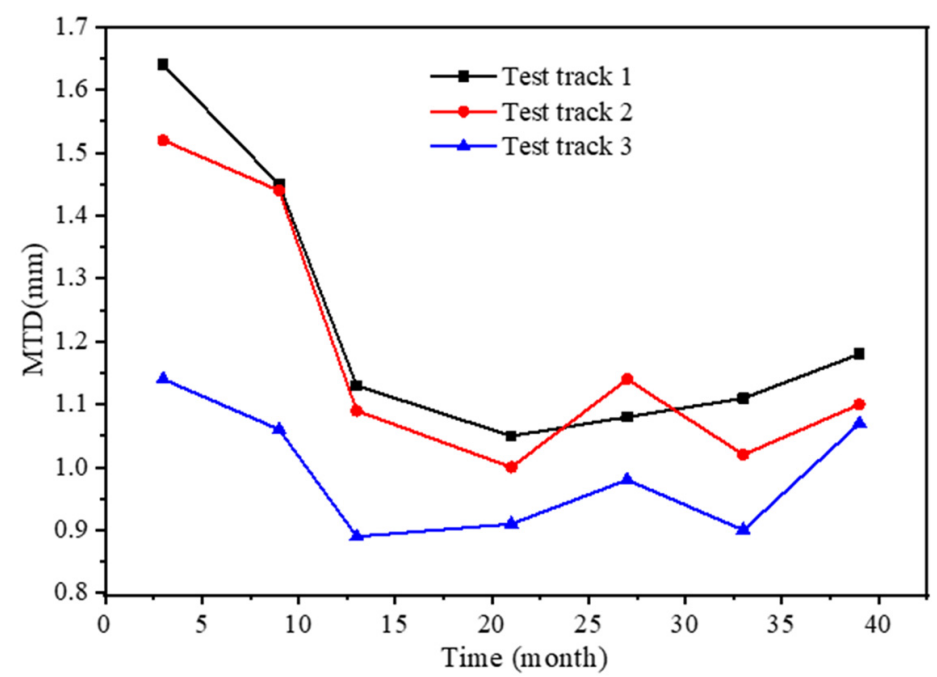

Figure 9. The MTD test results of different tracks.

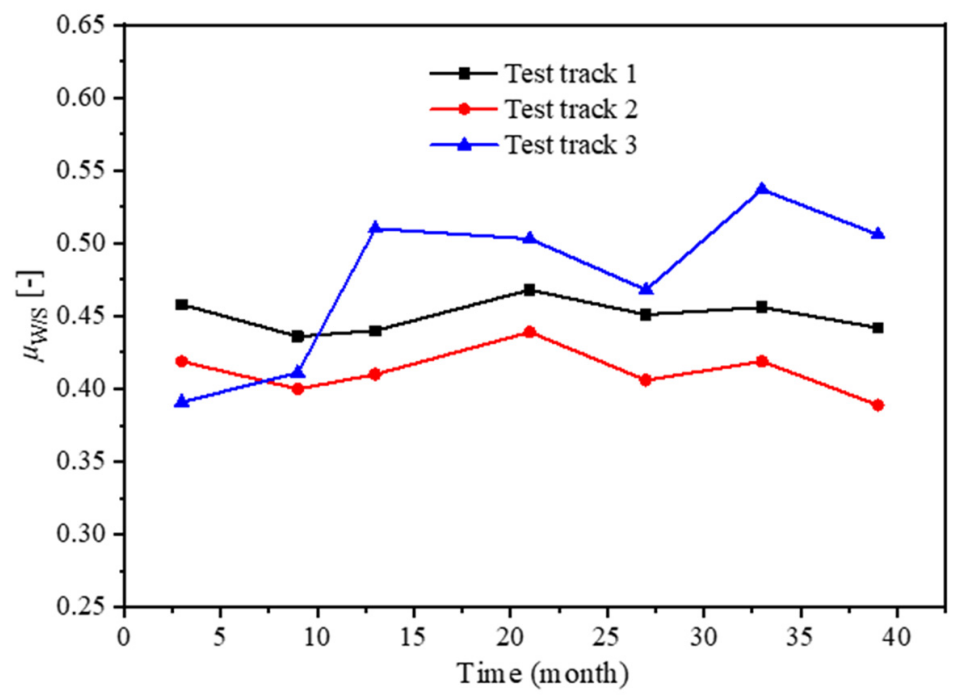

Figure 10. The W/S test results of different tracks. 


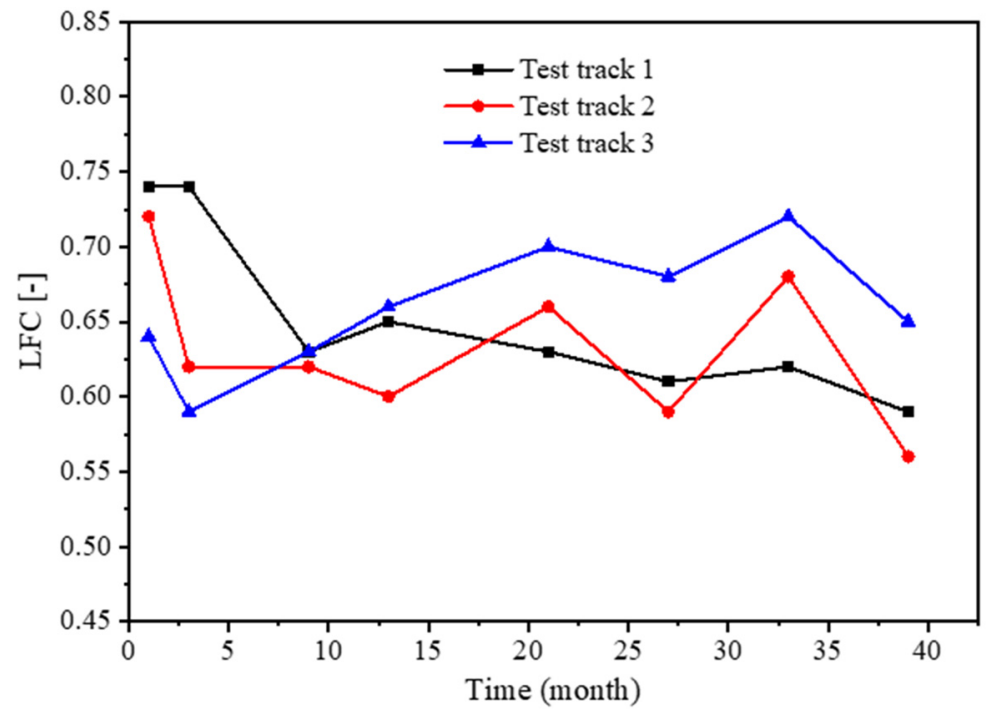

Figure 11. The LFC test results of different tracks.

\subsubsection{Empirical Models of Skid Resistance Deterioration}

For purpose of quantitatively describing the deterioration law of the skid resistance based on different parameters, the empirical models were established by fitting the test results through two function types which include logarithmic and quadratic polynomial functions. The selected fitting functions are also commonly used in the previous studies [33-36]. The fitting results were presented in Tables 3-7. It is seen from the tables that the quadratic polynomial function generally best describes the deterioration law of the BPN, OFT and MTD parameters. The evolutions of the $\mu_{\mathrm{W} / \mathrm{S}}$ and LFC parameters can be well characterized by the logarithmic function. It is also worth noting that the significant divergences in coefficient of correlation were observed for the fitting results of the LFC parameter. For the test track 1 , a high value of coefficient of correlation 0.89 indicates the effectiveness of the logarithmic fitting, but the value of coefficient of correlation 0.3 for the test track 2 implies the unavailability of the established empirical model. This is likely to be related to the fact that the LFC test can be affected by many factors when conducting the field test. The fitting results again demonstrate that the measurement of skid resistance is very complex, and the deterioration model must be established for different test methods.

Table 3. The fitting results of the BPN index.

\begin{tabular}{ccc}
\hline Test Track & Logarithmic Fitting & Quadratic Polynomial Fitting \\
\hline \multirow{2}{*}{1} & $y=-2.05 \ln (x)+65.23$ & $y=0.016 x^{2}-0.737 x+65.89$ \\
& $R^{2}=0.43$ & $R^{2}=0.68$ \\
2 & $y=-2.10 \ln (x)+63.96$ & $y=0.014 x^{2}-0.684 x+64.105$ \\
3 & $R^{2}=0.25$ & $R^{2}=0.33$ \\
& $y=-3.01 \ln (x)+51.24$ & $y=0.004 x^{2}-0.064 x+55.925$ \\
& $R^{2}=0.50$ & $R^{2}=0.66$ \\
\hline
\end{tabular}

Table 4. The fitting results of the OFT index.

\begin{tabular}{ccc}
\hline Test Track & Logarithmic Fitting & Quadratic Polynomial Fitting \\
\hline \multirow{2}{*}{1} & $y=-0.76 \ln (x)+0.91$ & $y=-0.001 x^{2}-0.096 x+1.61$ \\
& $R^{2}=0.69$ & $R^{2}=0.73$ \\
2 & $y=0.97 \ln (x)+0.62$ & $y=-0.003 x^{2}-0.170 x+1.22$ \\
3 & $R^{2}=0.83$ & $R^{2}=0.91$ \\
& $y=0.654 \ln (x)+2.90$ & $y=-0.001 x^{2}-0.085 x+3.47$ \\
& $R^{2}=0.50$ & $R^{2}=0.71$ \\
\hline
\end{tabular}


Table 5. The fitting results of the MTD index.

\begin{tabular}{ccc}
\hline Test Track & Logarithmic Fitting & Quadratic Polynomial Fitting \\
\hline \multirow{2}{*}{1} & $y=-0.217 \ln (x)+1.83$ & $y=0.001 x^{2}-0.059 x+1.80$ \\
& $R^{2}=0.76$ & $R^{2}=0.93$ \\
2 & $y=-0.207 \ln (x)+1.77$ & $y=0.001 x^{2}-0.047 x+1.70$ \\
& $R^{2}=0.68$ & $R^{2}=0.77$ \\
3 & $y=0.050 \ln (x)+0.34$ & $y=-0.0002 x^{2}+0.011 x+0.34$ \\
& $R^{2}=0.84$ & $R^{2}=0.83$ \\
\hline
\end{tabular}

Table 6. The fitting results of the $\mu_{\mathrm{W} / \mathrm{S}}$ index.

\begin{tabular}{ccc}
\hline Test Track & Logarithmic Fitting & Quadratic Polynomial Fitting \\
\hline \multirow{2}{*}{1} & $y=-0.027 \ln (x)+0.53$ & $y=0.0001 x^{2}-0.007 x+0.52$ \\
& $R^{2}=0.55$ & $R^{2}=0.49$ \\
2 & $y=-0.015 \ln (x)+0.46$ & $y=0.00003 x^{2}-0.002 x+0.45$ \\
3 & $R^{2}=0.50$ & $R^{2}=0.32$ \\
& $y=0.050 \ln (x)+0.34$ & $y=-0.0002 x^{2}-0.012 x+0.34$ \\
& $R^{2}=0.84$ & $R^{2}=0.83$ \\
\hline
\end{tabular}

Table 7. The fitting results of the LFC index.

\begin{tabular}{ccc}
\hline Test Track & Logarithmic Fitting & Quadratic Polynomial Fitting \\
\hline \multirow{2}{*}{1} & $y=-0.042 \ln (x)+0.753$ & $y=0.0001 x^{2}-0.009 x+0.74$ \\
& $R^{2}=0.89$ & $R^{2}=0.86$ \\
2 & $y=-0.022 \ln (x)+0.685$ & $y=0.00003 x^{2}-0.003 x+0.67$ \\
& $R^{2}=0.30$ & $R^{2}=0.18$ \\
3 & $y=0.021 \ln (x)+0.608$ & $y=-0.0001 x^{2}-0.007 x+0.60$ \\
& $R^{2}=0.43$ & $R^{2}=0.63$ \\
\hline
\end{tabular}

\subsubsection{Seasonal Variation of Skid Resistance}

To further analyze the potential influence of periodic climate changes in different seasons on the skid resistance performance of pavement, the differences between the measured and predicted values of the W/S test and the LFC test for test track 3 were plotted as shown in Figures 12 and 13, respectively. The regular fluctuations of the calculated difference indicate the cyclical changes of the pavement skid resistance with seasonal climate variation.

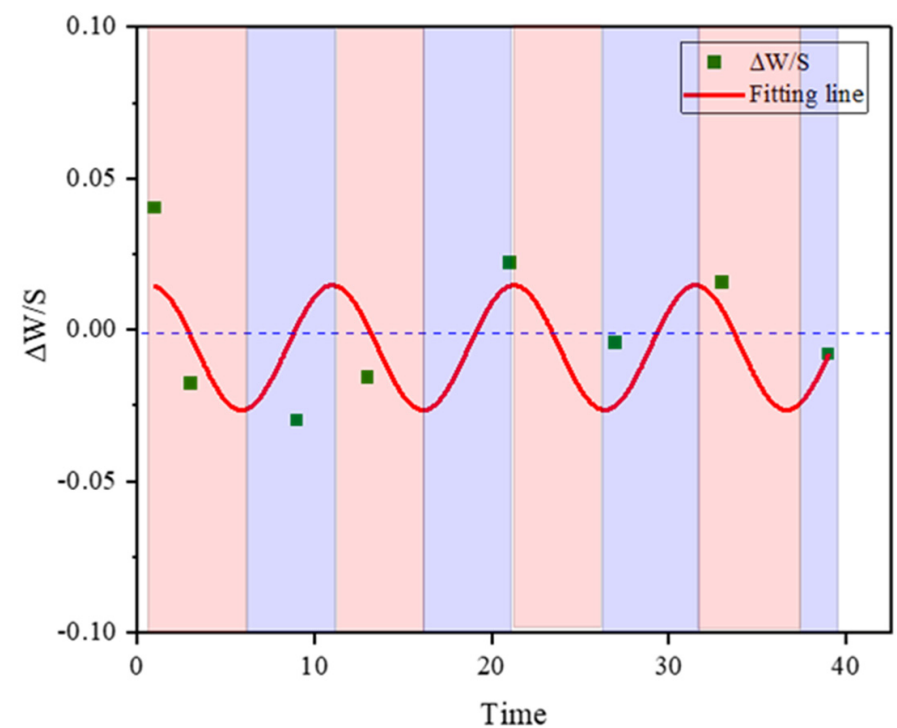

Figure 12. The regular fluctuation of $\Delta \mathrm{W} / \mathrm{S}$ with time for test track 2. 


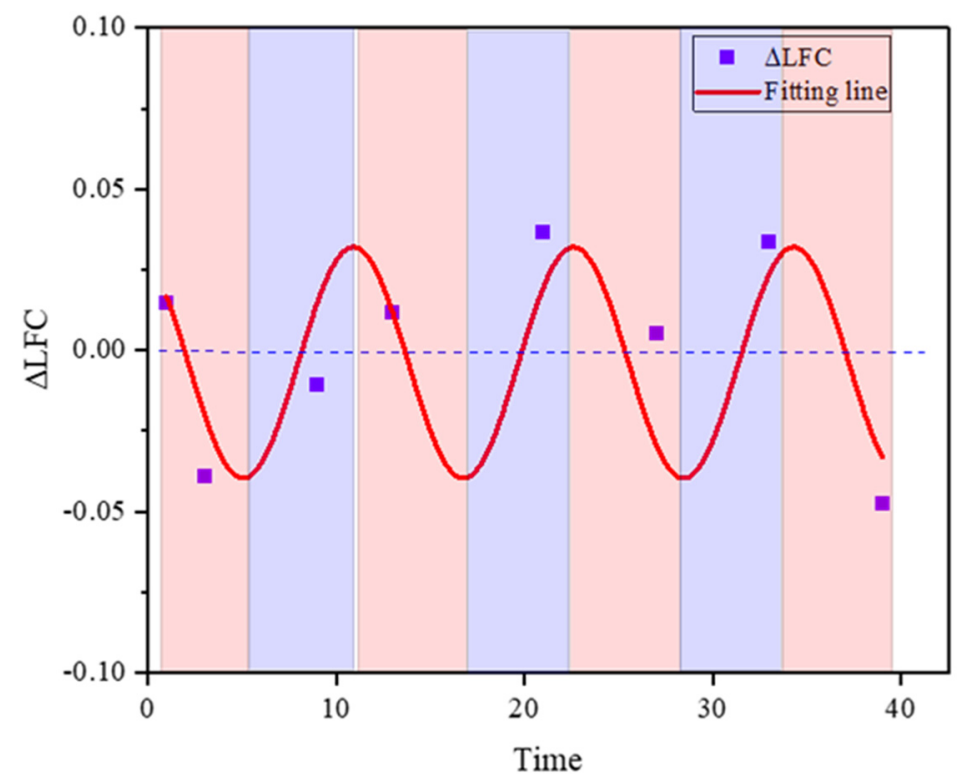

Figure 13. The regular fluctuation of $\triangle \mathrm{LFC}$ with time for test track 3.

Furthermore, the measurement results of different test tracks were grouped as spring, summer, and autumn categories. Then the group values were averaged, and the seasonable averaged skid resistance measured by different methods were shown in Figures 14-18.

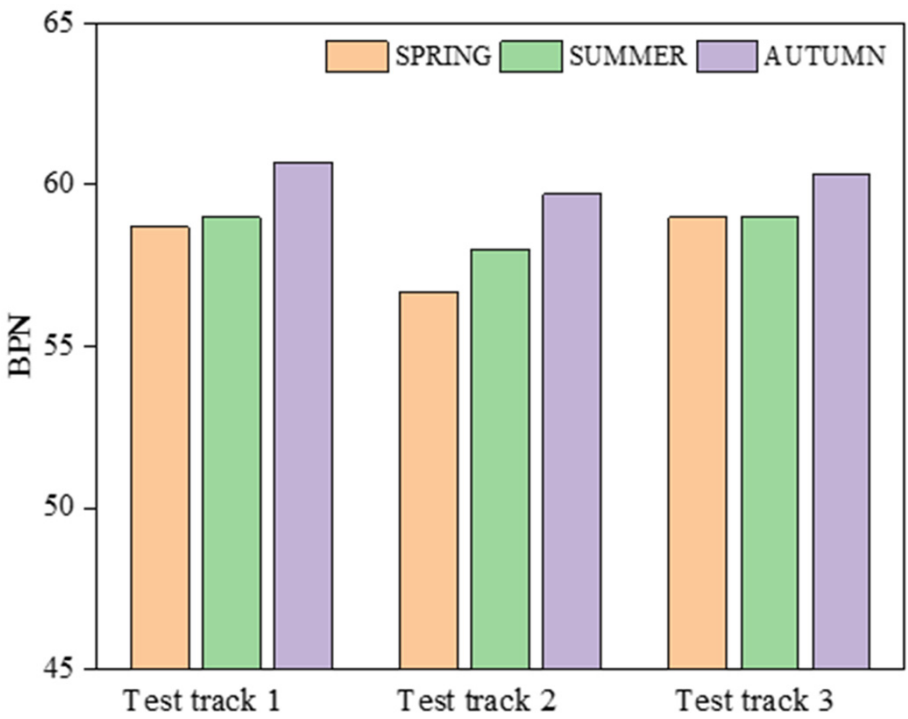

Figure 14. Seasonal averaged BPN values of different test tracks.

The results from Figures 14-18 indicate that the measured results of the five selected indexes show significant seasonal dependency. However, it should be mentioned that no uniform rule can be identified regarding the detailed influence of season for the five tests. The highest values of the BPN and MTD parameters always occur in autumn, and lowest values of the MTD parameter always occur in summer. This is in good agreement with the conclusions from previous studies $[15,16]$. The results from Figures 14-18 again validate the complexity of skid resistance measurement. Further calibration works are still in need to figure out an effective test method. 


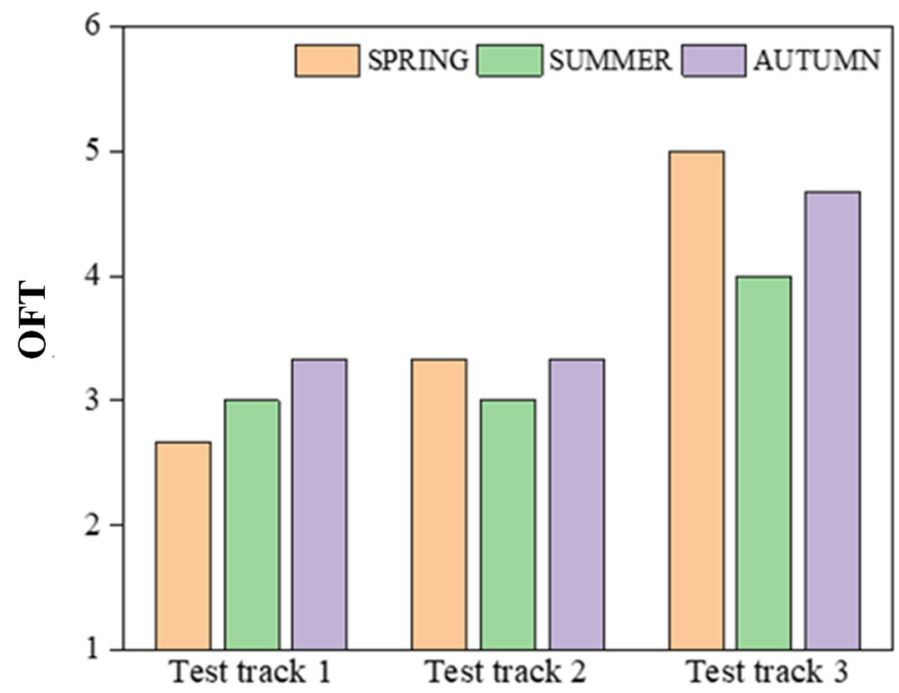

Figure 15. Seasonal averaged OFT values of different test tracks.

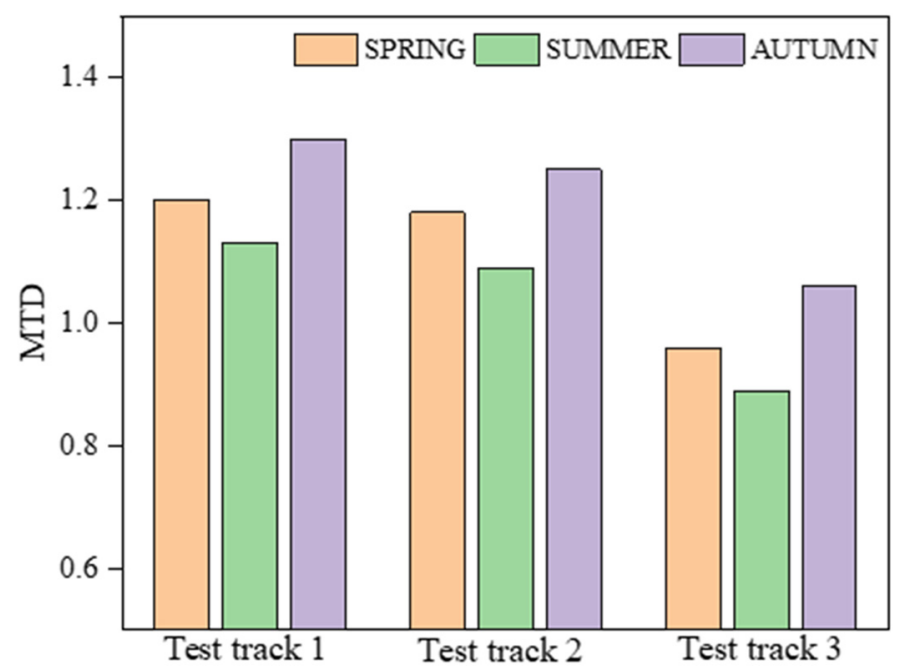

Figure 16. Seasonal averaged MTD values of different test tracks.

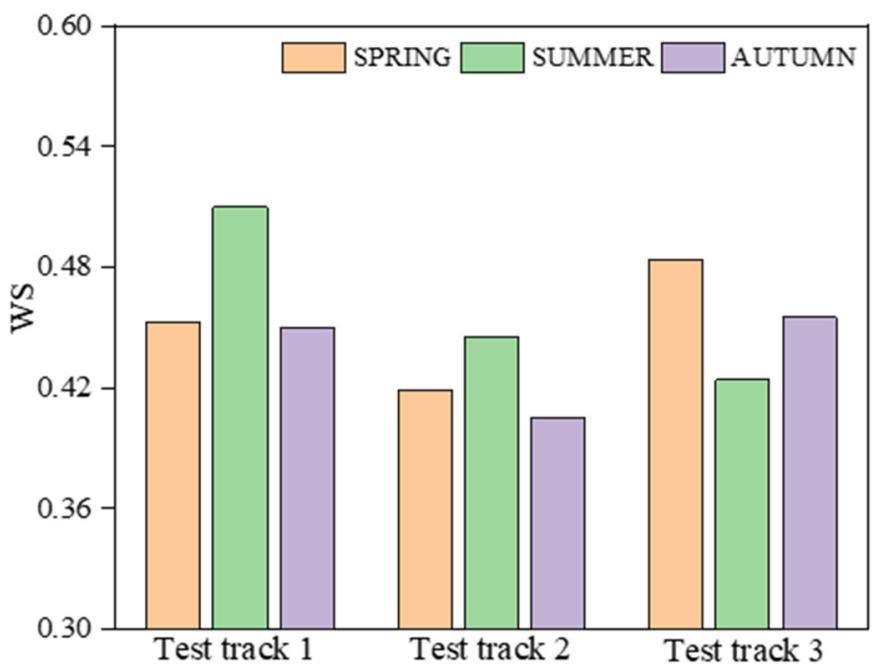

Figure 17. Seasonal averaged $\mu_{\mathrm{W} / \mathrm{S}}$ values of different test tracks. 


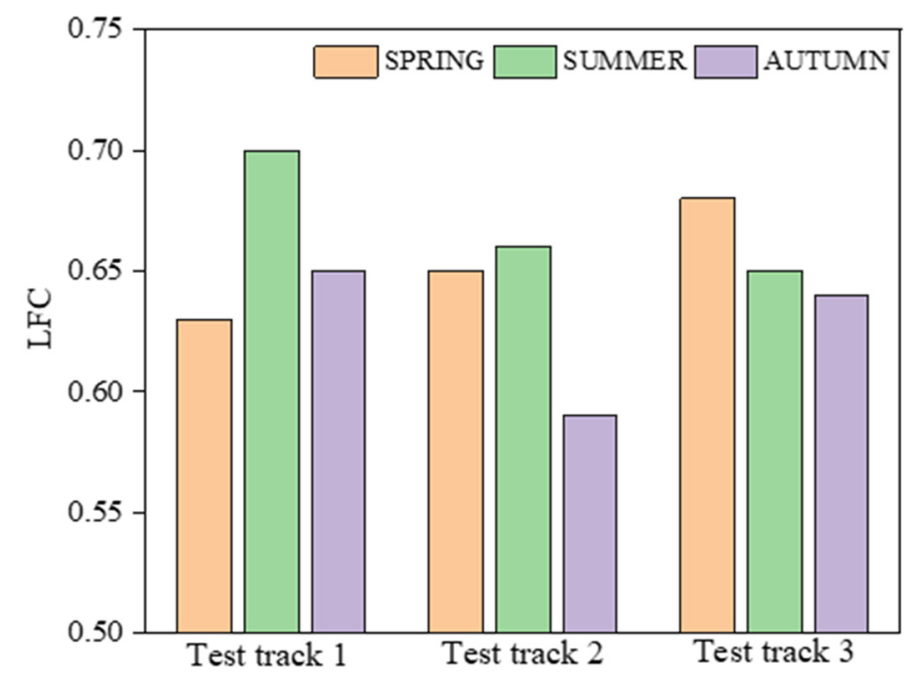

Figure 18. Seasonal averaged LFC values of different test tracks.

\subsubsection{Sensitivity Analysis of Influencing Factors}

To exploit the potential influence of the factors like aggregate type, traffic loading time and season type, a sensitivity analysis was further conducted by using the SPSS to conduct the variance analysis, and the detailed results were presented in Table 8 . The calculated values in the table represent the degree of influence of the sensitivity factor on the test results, and a value greater than 0.05 validates that the influence is statistically significant. Conclusions can be drawn that the BPN parameter is highly sensitive to the aggregate type. This is because the BPT test is a special kind of low-speed and is a microtexture-based test, while the aggregate type is a major factor that affects the microtexture deterioration of pavement surface. It can also be found that the MTD and OFT parameters show high sensitivity to aggregate type and traffic load time. This is reasonable considering that aggregate type and polishing time are the crucial factors that determine the final value of texture deterioration.

Table 8. Analysis of sensitivity factor.

\begin{tabular}{cccccc}
\hline Sensitivity Factor & BPN & OFT & MTD & $\mu_{\text {W/S }}$ & LFC \\
\hline Aggregate type & 0.686 & 0.003 & 0.063 & 0.186 & 0.543 \\
Load time & 0.051 & 0.176 & 0.020 & 0.905 & 0.312 \\
Season Type & 0.431 & 0.849 & $0.448^{*}$ & 0.714 & 0.236 \\
\hline
\end{tabular}

Note: At the 0.05 level ${ }^{*}$ (double-tailed), the correlation is credible.

\subsection{Correlation Analysis of the Skid Resistance Tests}

\subsubsection{Correlation of the Laboratory Tests}

Previous research works have demonstrated that the skid resistance measurement results obtained through different tests generally show very poor correlations [37,38]. A correlation analysis was also conducted to validate the correlations between different laboratory tests which were used in this study. The correlation analysis results were given in Table 9. Table 9 clearly shows that the OF test result is highly related to that of the MTD test with a correlation coefficient of -0.848 . The negative value is reasonable considering the physical meaning of the parameters. The correlation coefficient between the W/S test and OFT test is -0.59 , which is slightly higher than the value (0.418) between MTD test and $\mathrm{W} / \mathrm{S}$ test. In comparison, the BPT test shows no significant correlation with all other three laboratory tests. 
Table 9. Correlation of the between laboratory tests.

\begin{tabular}{ccccc}
\hline Sensitivity Factor & BPN & OFT & MTD & $\mu_{W / S}$ \\
\hline BPN & 1.000 & -0.006 & 0.312 & 0.367 \\
OFT & & 1.000 & -0.848 & -0.590 \\
MTD & & & 1.000 & 0.418 \\
$\mu_{W / S}$ & & & 1.000 \\
\hline
\end{tabular}

Note: At the 0.05 level (double-tailed), the correlation is credible.

\subsubsection{Correlation between Field and Laboratory Tests}

Among the five adopted tests in the current study, the LFC test is the only field test that has been extensively used in different countries. Correlation study was also performed to exploit the correlation between the field and laboratory tests, and results were seen in Figures 19-22. It is found that the correlation coefficient between the LFC test and W/S test is 0.4519 , which is obviously higher than that of the other three pairs. This indicates that the W/S test is a more realistic guide than the other methods in evaluating the field skid resistance of asphalt pavement. Therefore, special concern must be given to these laboratory tests when investigating the skid resistance of asphalt pavement using them.

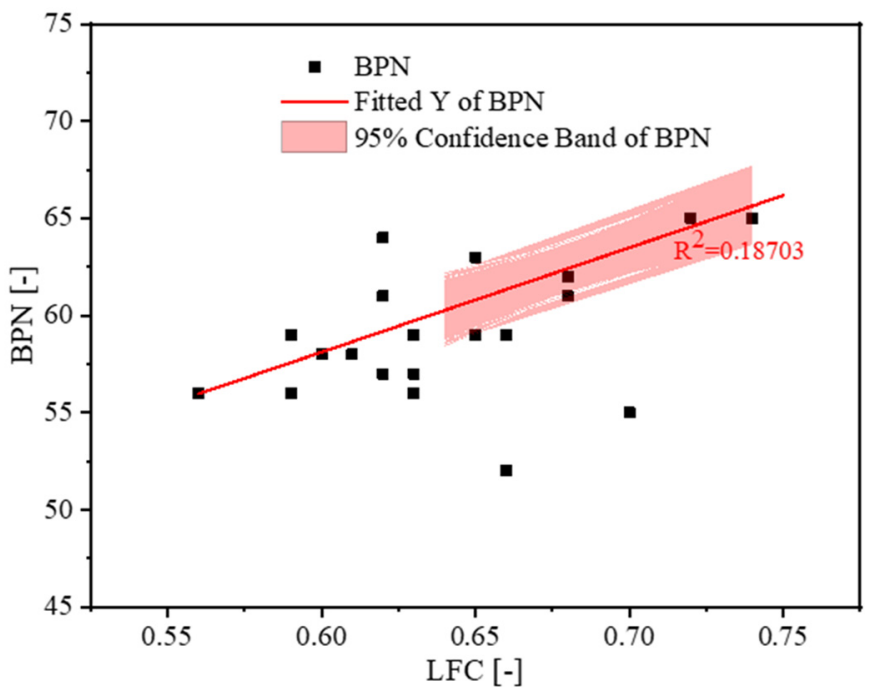

Figure 19. Correlation analysis between LFC and BPN.

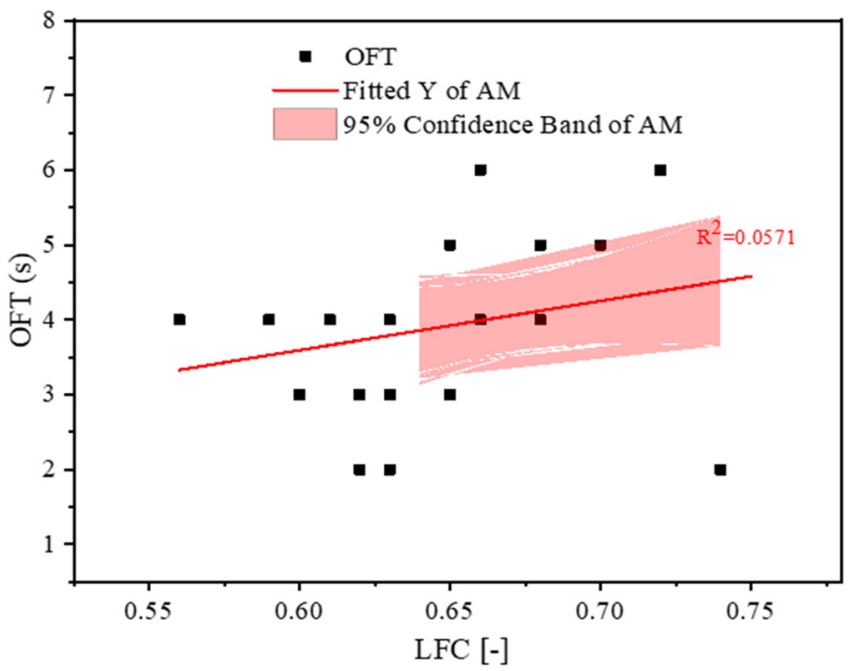

Figure 20. Correlation analysis between LFC and OFT. 


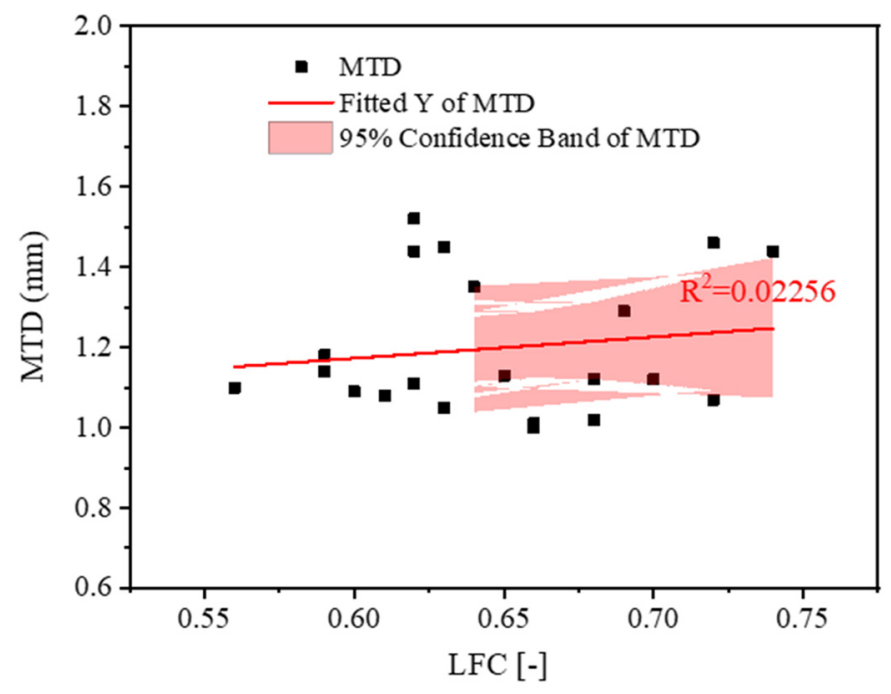

Figure 21. Correlation analysis between LFC and MTD.

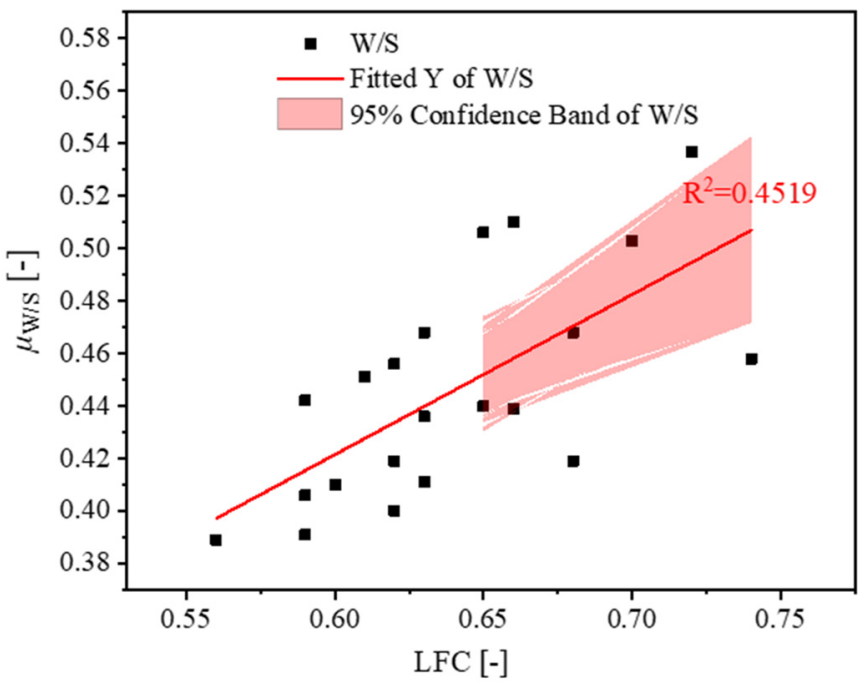

Figure 22. Correlation analysis between LFC and $\mu_{\mathrm{W} / \mathrm{s}}$.

\subsection{Synthetical Index Analysis of Skid Resistance}

\subsubsection{Synthetical Index Method}

The synthetical index method was used to compare and analyze the differences in skid resistance of the test tracks as well as their deterioration behavior. A comprehensive index was used to describe the performance in this method. Considering that each test method has its own advantages and disadvantages, it is necessary to integrate the advantages of all the tests to accurately characterize the skid resistance of asphalt pavement. The synthetical index method has the high reliability and uniform index to characterize the skid resistance.

The synthetical index method is a basic method of data analysis which assigns coefficients to each subindex according to the attributes or inherent laws. Then the average values are calculated for all the subindexes, and they are finally converted to obtain the synthetical index as described through Equations (1) and (2).

$$
\begin{gathered}
\overline{\overline{X_{q}}}=\frac{1}{n} \sum_{q=1}^{n} a_{q} \times \overline{X_{q}} \\
\overline{X_{q}}=\frac{1}{n} \sum_{q=1}^{n} X_{q}
\end{gathered}
$$


where $\overline{\overline{X_{q}}}$ is the synthetical index, $\overline{X_{q}}$ is the average value of the subindex, $a_{q}$ is the weight coefficient.

\subsubsection{Skid Resistance Deterioration Analysis Based on Synthetical Index}

The synthetical index was calculated for the three test tracks to probe the skid resistance deterioration behaviors. Considering that the skid resistance of pavement is directly related to the surface texture, the current study gives first priority to the parameter MTD. Therefore, the weight of MTD was defined as 1, and the correlation coefficients between MTD and other four parameters were adopted as their weights, respectively. This implies that the calculation values of $a_{q}$ for the MTD, BPN, OFT, $\mu_{W / S}$ and LFC are $1,0.312,0.848,0.418$, and 0.757 , respectively. The calculated synthetical indexes for the three test tracks were given in Figure 23.

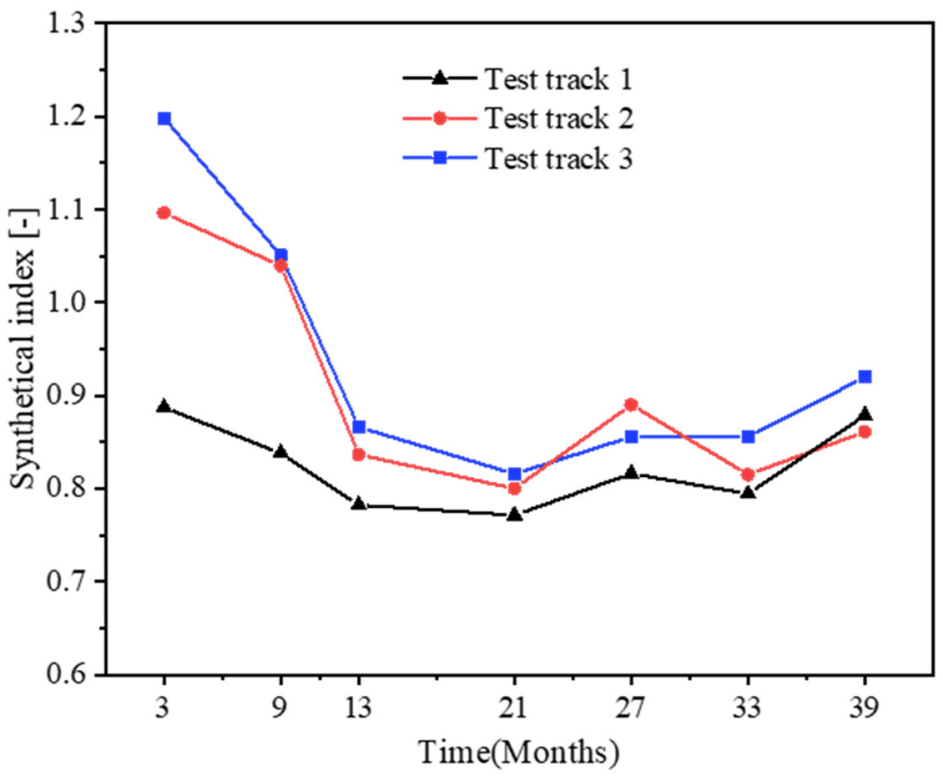

Figure 23. The calculated synthetical indexes of the test tracks.

It could be found from Figure 23 that the skid resistance of the three test tracks can be ranked as test track $3>$ test track $2>$ test track 1 . This ranking is believed to be closely related to the mineralogical characteristics and polishing resistance of the three aggregates used for different test tracks as shown in Section 2.1. Among the three selected aggregates, the greywacke aggregate shows the best polishing resistance, and therefore, the test track 3 , which is comprised of greywacke aggregate, exhibits best skid resistance. The test track 1 shows the worst skid resistance, and the rhyolite aggregate used in it also has the worst polishing resistance. Meanwhile, it is also found that the three test tracks show a similar trend of the deterioration of skid resistance. The skid resistance of asphalt pavement continuously decreases at the first 21 months and then turns to be constant with slight fluctuation. This result is in well agreement with the stage II and stage III behavior of the classical deterioration law as has been identified in our previous study [14] considering that the selected three test tracks have serviced for two years before the tests were performed. This implies that the skid resistance prediction model established based on the laboratory test is effective in describing the skid resistance evolution behavior of asphalt pavement.

\subsubsection{Seasonal Variation Analysis Based on Synthetical Index}

The synthetical index was also used to investigate the seasonal variation of pavement skid resistance because this method has the advantage of eliminating the influence of discreteness arising from the aggregate type and test method. It is found that the calculated synthetical indexes for different seasons can be ranked as autumn $>$ spring $>$ summer, as seen in Figure 24. This phenomenon can be attributed to the influence of temperature on 
the adhesion of tire to pavement surface. In spring and autumn, the mild temperature leads to a higher value of tire-pavement adhesion, and therefore, better skid resistance was observed. In comparison, the average temperature in autumn is higher than in spring, which leads to better skid resistance in autumn. In summer, the high temperature makes the asphalt pavement soft, and the aggregates at the surface layer are further compacted by the vehicles. As a result, the pavement surface becomes smoother, which further decreases the skid resistance of asphalt pavement. Considering the seasonal variation of pavement skid resistance, the skid resistance measured in the summer should be used as the limit value in the future.

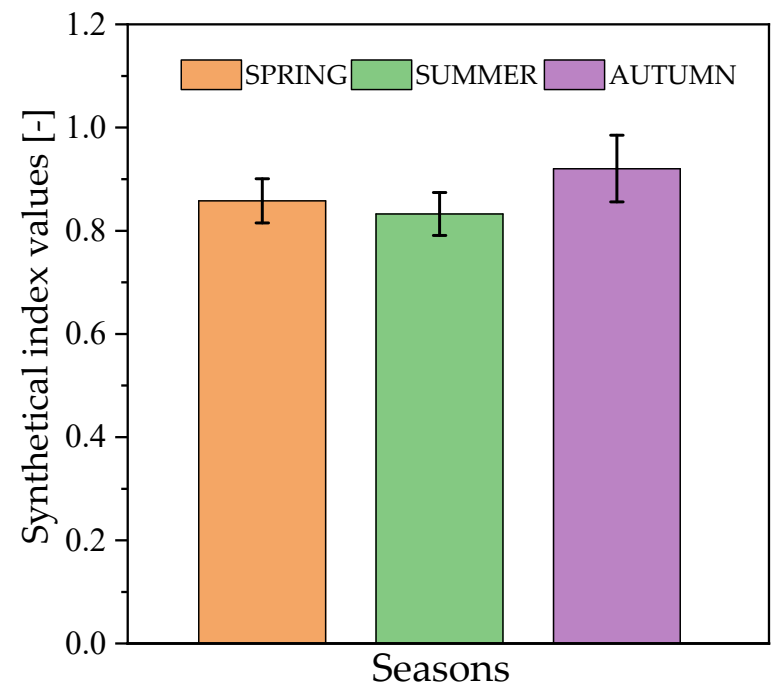

Figure 24. The calculated synthetical indexes of different seasons.

\section{Conclusions}

In this study, five different test methods were adopted to continuously measure the long-term skid resistance of three test tracks. The selected test tracks are composed of SMA-11S asphalt mixture. Based on the test results, the influences of test method, aggregate type and seasonal climate on skid resistance were identified. The major conclusions from this study include the following:

(1) The selection of well-performed test equipment and reasonable evaluation method is the prerequisite of skid resistance research. The five adopted tests in the current study generally show very different test results owing to their difference in evaluation object and test condition.

(2) The laboratory W/S test-based polishing resistance evaluation for aggregate is found to show good agreement with that of the W/S and LFC field tests, which provides important foundation for the future laboratory prediction of skid resistance.

(3) The aggregate type is found to significantly influence the skid resistance of asphalt pavement. For the three test tracks selected in this study, the test track using greywacke aggregate shows the best skid resistance, whereas the one composed of rhyolite aggregate exhibits the worst skid resistance. The greywacke aggregate is recommended to be used in the surface layer for future construction of durable asphalt pavements.

(4) Significant variation was observed for the skid resistance of asphalt pavement at the early service stage of asphalt pavement because the bitumen film of the pavement surface was polished by the coupling effect of vehicle and climate factors. The magnitude of this variation is closely related to the affinity property between bitumen and aggregate.

(5) In the long term, the skid resistance of asphalt pavement becomes relatively stable, but the cyclical changing climate still shows obvious influence on it. The measured skid resistances of the test tracks in different seasons were ranked as autumn > spring > sum- 
mer. The skid resistance of asphalt pavement in summer is suggested to be used as the control index for the pavement management and maintenance design.

The current study is based on the measurement results of three test tracks, and the relevant conclusions remain to be further validated based on more test data in the future work. Meanwhile, more than twenty different kinds of test methods for pavement skid resistance have been reported, but only five were adopted in the current study. The comprehensive correlation analysis regarding these different tests should be performed.

Author Contributions: Data curation, J.W. and Z.Z.; Formal analysis, J.W., Z.Z. and X.Y.; Funding acquisition, D.W.; Investigation, Y.H. and Q.T.; Supervision, D.W. and M.O.; Validation, M.O.; Writingoriginal draft, J.W. All authors have read and agreed to the published version of the manuscript.

Funding: This research was funded by -German Research Foundation (DFG), grant number OE 514/15-1 (459436571).

\section{Institutional Review Board Statement: Not applicable.}

Informed Consent Statement: Not applicable.

Data Availability Statement: The data presented in this study are available on request from the corresponding author. The data are not publicly available due to confidentiality promised to research participants.

Acknowledgments: The authors would like to thank all reviewers for their valuable comments on this thesis, which allowed us to find many details worthy of improvement and made our paper more clear and complete.

Conflicts of Interest: The authors declare no conflict of interest.

\section{References}

1. Armengol, J.M.; Salinas, C.T.; Xaman, J.; Ismail, K.A.R. Modeling of frost formation over parallel cold plates considering a two-dimensional growth rate. Int. J. Therm. Sci. 2016, 104, 245-256. [CrossRef]

2. Rezaei, A.; Masad, E.; Chowdhury, A. Development of a model for asphalt pavement skid resistance based on aggregate characteristics and gradation. J. Transp. Eng. 2011, 137, 863-873. [CrossRef]

3. Ech, M.; Yotte, S.; Morel, S.; Breysse, D.; Pouteau, B. Qualification of wearing course material surface evolution after durability test. Constr. Build. Mater. 2012, 35, 313-320. [CrossRef]

4. He, Y.; Xing, C.; Hong, B.; Tan, Q.; Wang, D.; Oeser, M. Study on the Influence of Polishing Value of Thick and Fine Aggregates on Long-term Skid Resistance of Asphalt Pavement. China J. Highw. Transp. 2021. Available online: https://kns.cnki.net/kcms/ detail/61.1313.u.20211011.1546.002.html (accessed on 28 December 2021).

5. Gerardo, F.W.; Edgar, D.L.; Kevin, K.; Imad, L.A.-Q. Pavement Surface macro texture measurement and application. Transp. Res. Rec. 2003, 1860, 168-177.

6. Kokkalis, A.G.; Tsohos, G.H.; Panagouli, O.K. Consideration of fractals potential in pavement skid resistance evaluation. J. Transp. Eng. 2002, 128, 591-595. [CrossRef]

7. Kane, M.; Artamendi, I.; Scarpas, T. Long-term Skid Resistance of Asphalt Surfacing: Correlation Between Wehner-Schulze Friction Values and the Mineralogical Composition of the Aggregates. Wear 2013, 303, 235-243. [CrossRef]

8. Lahayne, O.; Pichler, B.; Reihsner, R.; Eberhardsteiner, J.; Suh, J.; Kim, D.; Nam, S.; Paek, H.; Lorenz, B.; Persson, B.N.J. Rubber Friction on Ice: Experiments and Modeling. Tribol. Lett. 2016, 62, 17. [CrossRef]

9. Huschek, S. The grip forecast with the traffic simulation. Bitumen 2002, 64, 14-18.

10. Editorial Department of China Journal of Highway and Transport. Review on China's Pavement Engineering Research. China J. Highw. Transp. 2020, 33, 1-66.

11. Ma, B.; Liu, Y.; Lv, C.; Zhang, M.; Ji, X.; Zhang, M. Estimation of Road Adhesion Coefficient Based on Tire Aligning Torque Distribution. J. Dyn. Syst. Meas. Control 2018, 140, 051010. [CrossRef]

12. Persson, B.N.J. Theory of rubber friction and contact mechanics. J. Chem. Phys. 2001, 115, 3840-3861. [CrossRef]

13. Lopez, M.; Zhao, M.; Chaillexue, E.; Kane, M.; Gabet, T.; Petiteu, C. Characterization of aging processes on asphalt mixture Surface. In Proceedings of the ISAP, Fortaleza, Nagoya, Japan, 29 October-2 November 2012; pp. 413-419.

14. Lu, G.; He, Y.; Zhen, L.; Wang, D.; Hong, B.; Xiong, J.; Wei, J.; Oeser, M. Comparison of the Polishing Resistances of Concrete Pavement Surface Textures Prepared with Different Technologies Using the Aachen Polishing Machine. J. Mater. Civ. Eng. 2021, 33, 04021226.

15. Hu, J.; Qian, Z.; Wang, D.; Oeser, M. Influence of aggregate particles on mastic and air-voids in asphalt concrete. Constr. Build. Mater. 2015, 93, 1-9. [CrossRef]

16. Mala, K.; Piau, J.; Do Winh, T. On the study of polishing of road surface under traffic load. J. Transp. Eng. 2010, $236,45-51$. 
17. Dunford, A.M.; Parry, A.R.; Shipway, P.H.; Bruns, H. Three-dimensional characterization of surface texture for road stones undergoing simulated traffic wear. Wear 2012, 292-293, 188-196. [CrossRef]

18. Artamendi, I.; Phillips, P.; Allen, B.; Woodward, W.D.H. An assessment of the evolution of the skid resistance of proprietary asphalt surfacing in the UK. In Proceedings of the Fifth Euroasphalt \& Eurobitume Congress, Istanbul, Turkey, $12-15$ June 2012.

19. Artamendi, I.; Khalid, H. Characterization of fatigue damage for paving asphaltic materials. Fatigue Fract. Eng. Mater. Struct. 2010, 28, 1113-1118. [CrossRef]

20. Wang, H.; Wang, Z. Evaluation of pavement surface friction subject to various pavement preservation treatments. Constr. Build. Mater. 2013, 48, 194-202. [CrossRef]

21. Giles, C.; Sabey, B.E.; Cardew, K. Development and performance of the portable skid resistance tester. Rubber Chem. Technol. 1965, 38, 840-862. [CrossRef]

22. Ergun, M.; Iyinam, S.; Iyinam, A.F. Prediction of road surface friction coefficient using only macro- and microtexture measurements. J. Transp. Eng. 2005, 131, 311-319. [CrossRef]

23. Wang, D.; Chen, X.; Yin, C.; Oeser, M.; Steinauer, B. Influence of different polishing conditions on the skid resistance development of asphalt surface. Wear 2013, 308, 71-78. [CrossRef]

24. Ueckermann, A.; Wang, D.; Oeser, M.; Steinauer, B. A contribution to non-contact skid resistance measurement. Int. J. Pavement Eng. 2015, 16, 646-659. [CrossRef]

25. Ueckermann, A.; Wang, D.; Oeser, M.; Steinauer, B. Calculation of skid resistance from texture measurements. J. Traffic Transp. Eng. 2015, 2, 3-16. [CrossRef]

26. Fwa, T.; Choo, Y.; Liu, Y. Effect of aggregate spacing on skid resistance of asphalt pavement. J. Transp. Eng. 2003, 129, 420-426. [CrossRef]

27. Liu, Y.; Fwa, T.; Choo, Y. Effect of surface macrotexture on skid resistance measurements by the british pendulum test. J. Test. Eval. 2004, 32, 304-309. [CrossRef]

28. Henry, J.; Hegmon, R. Pavement Texture Measurement and Evaluation; ASTM Special Technical Publication: West Conshohocken, PA, USA, 1975; pp. 3-17.

29. Moore, D.F. Prediction of skid-resistance gradient and drainage characteristics for pavements. Highw. Res. Rec. 1966, 131, 181-203.

30. Yu, M.; You, Z.; Wu, G.; Kong, L.; Gao, J. Measurement and modeling of skid resistance of asphalt pavement: A review. Constr. Build. Mater. 2020, 260, 119878. [CrossRef]

31. Wang, D.; Liu, P.; Wang, H.; Ueckermann, A.; Oeser, M. Modeling and Testing of Road Surface Aggregate Wearing Behaviour. Constr. Build. Mater. 2017, 131, 129-137. [CrossRef]

32. Wang, D.; Zhang, Z.; Kollmann, J.; Oeser, M. Development of Aggregate Micro-texture during Polishing and Correlation with Skid Resistance. Int. J. Pavement Eng. 2020, 21, 629-641. [CrossRef]

33. Chen, X.; Steinauer, B.; Wang, D. Evolution of Aggregate Surface Micro-Texture Due to Tire-Polishing. J. Cent. South Univ. Technol. 2018, 18, 259-265. [CrossRef]

34. Do, M.T.; Tang, Z.; Kane, M.; de Larrard, F. Pavement Polishing-Development of a dedicated laboratory test and its correlation with road results. Wear 2007, 263, 36-42. [CrossRef]

35. Do, M.T.; Tang, Z.; Kane, M.; Larard, F.D. Evolution of road-surface skid-resistance and texture due to polishing. Wear 2009, 266, 574-577. [CrossRef]

36. Wilson, D.J. An Analysis of the Seasonal and Short-Term Variation of Road Pavement Skid Resistance. Ph.D. Thesis, Department of Civil and Environmental Engineering, The University of Auckland, Auckland, New Zealand, 2006.

37. Ren, W.; Han, S.; He, Z.; Li, J.; Wu, S. Development and testing of a multivariable accelerated abrasion machine to characterize the polishing wear of pavement by tires. Surf. Topogr. Metrol. Prop. 2019, 2019, 1-16. [CrossRef]

38. Bazlamit, M.; Reza, F. Changes in asphalt pavement friction components and adjustment of skid number for temperature. J. Transp. Eng. 2005, 131, 470-476. [CrossRef] 